\title{
USING CALIBRATED RGB IMAGERY FROM LOW-COST UAVS FOR GRASSLAND MONITORING: CASE STUDY AT THE RENGEN GRASSLAND EXPERIMENT (RGE), GERMANY
}

\author{
U. Lussem ${ }^{\mathrm{a}, * *}$, J. Hollberg ${ }^{\mathrm{b}, \mathrm{d}}$, J. Menne ${ }^{\mathrm{a}}$, J. Schellberg ${ }^{\mathrm{c}, \mathrm{d}}$, G. Bareth ${ }^{\mathrm{a}, \mathrm{d}}$ \\ ${ }^{\text {a }}$ Institute of Geography, GIS \& Remote Sensing Group, University of Cologne, Albertus-Magnus-Platz, 50923 Cologne, \\ Germany - (ulrike.lussem, g.bareth)@uni-koeln.de, jmenne@gmx.de \\ ${ }^{\mathrm{b}}$ Institute of Crop Science and Resource Conservation, Crop Science Group, University of Bonn, Katzenburgweg 5, 53115 \\ Bonn, Germany - jens.hollberg@uni-bonn.de \\ ${ }^{\mathrm{c}}$ Institute of Crop Science and Resource Conservation, Agro- and Production Ecology, University of Bonn, Auf dem Hügel \\ 6, 53121 Bonn, Germany -j.schellberg@uni-bonn.de \\ ${ }^{\mathrm{d}}$ ZFL - Center for Remote Sensing of Land Surfaces, University of Bonn, Genscherallee 3, 53113 Bonn, Germany
}

KEY WORDS: grassland monitoring, low-cost UAVs, RGB vegetation indices, empirical line calibration

\begin{abstract}
:
Monitoring the spectral response of intensively managed grassland throughout the growing season allows optimizing fertilizer inputs by monitoring plant growth. For example, site-specific fertilizer application as part of precision agriculture (PA) management requires information within short time. But, this requires field-based measurements with hyper- or multispectral sensors, which may not be feasible on a day to day farming practice. Exploiting the information of RGB images from consumer grade cameras mounted on unmanned aerial vehicles (UAV) can offer cost-efficient as well as near-real time analysis of grasslands with high temporal and spatial resolution. The potential of RGB imagery-based vegetation indices (VI) from consumer grade cameras mounted on UAVs has been explored recently in several. However, for multitemporal analyses it is desirable to calibrate the digital numbers (DN) of RGB-images to physical units. In this study, we explored the comparability of the RGBVI from a consumer grade camera mounted on a low-cost UAV to well established vegetation indices from hyperspectral field measurements for applications in grassland. The study was conducted in 2014 on the Rengen Grassland Experiment (RGE) in Germany. Image DN values were calibrated into reflectance by using the Empirical Line Method (Smith \& Milton 1999). Depending on sampling date and VI the correlation between the UAV-based RGBVI and VIs such as the NDVI resulted in varying $\mathrm{R}^{2}$ values from no correlation to up to 0.9 . These results indicate, that calibrated RGB-based VIs have the potential to support or substitute hyperspectral field measurements to facilitate management decisions on grasslands.
\end{abstract}

\section{INTRODUCTION}

Monitoring the spectral response of intensively managed grassland throughout the growing season allows optimizing fertilizer inputs by monitoring plant growth. For example, site-specific fertilizer application as part of precision agriculture (PA) management requires information within short time (Schellberg et al. 2008). But, this requires field-based measurements with hyper- or multispectral sensors which are relatively expensive, have a limited spatial coverage, require expert-knowledge in operating and are time-consuming when applied on fieldscale. Hyperspectral sensors may not be feasible on a day to day farming practice. Exploiting the information of RGB images from consumer grade cameras mounted on unmanned aerial vehicles (UAV) can offer cost-efficient as well as near-real time analysis of grasslands with high temporal and spatial resolution (Hunt et al. 2013).

The potential of RGB imagery-based vegetation indices (VI) from consumer grade cameras mounted on UAVs has been explored recently in several studies (Bendig et al.
2015, Hunt et al 2005; 2011; 2013, Bareth et al. 2015, Rasmussen et al. 2016). These studies indicate a good correlation of RGB-based VIs with established VIs using the VIS-, NIR- or SWIR domains, such as the NDVI. A new, moderately performing RGB-based VI, the RGBVI, was introduced by Bendig et al. (2015) and evaluated by Tilly et al. (2015) and Bareth et al. (2015) against hyperspectral field spectrometer measurements. However, these studies applied no method to calibrate the digital numbers (DN) of the RGB images into physical units of reflectance. However, this is a desirable approach for multitemporal image analysis, such as monitoring grassland throughout the growing season.

In this study, we explored the comparability of RGB-based VIs from a consumer grade camera mounted on a low-cost UAV to well established vegetation indices from hyperspectral field measurements for applications in grassland. The study was conducted in 2014 on the Rengen Grassland Experiment (RGE) in Germany.

\footnotetext{
${ }^{*}$ Corresponding author
} 


\section{STUDY AREA \& METHODS}

The Rengen Grassland Experiment (RGE) is located in the Eifel mountain Region and was established 1941. The RGE comprises 55 plots ( $3 \times 5$ meter) with ten replicates of five fertilizer treatments that are applied annually $(\mathrm{Ca}$, $\left.\mathrm{CaN}, \mathrm{CaNP}, \mathrm{CaNPKCl}, \mathrm{CaNPK}_{2} \mathrm{SO}_{4}\right)$. Five untreated plots serve as control plots (Schellberg et al 1999). The RGE is a two-cut regime with one harvest at the beginning of July and one in mid-October. The long-term fertilizer application resulted in distinct floristic compositions per plot, varying in their morphological and optical features (Chytry et al. 2009). The RGE is managed by the INRES Group of Bonn University. The hyperspectral field measurements were carried out within the DFG funded project "Detecting the response of plant functional traits to nutrient status in grassland by spectral reflectance measurements" , coordinated by the Crop Science Group of Bonn University, Germany.

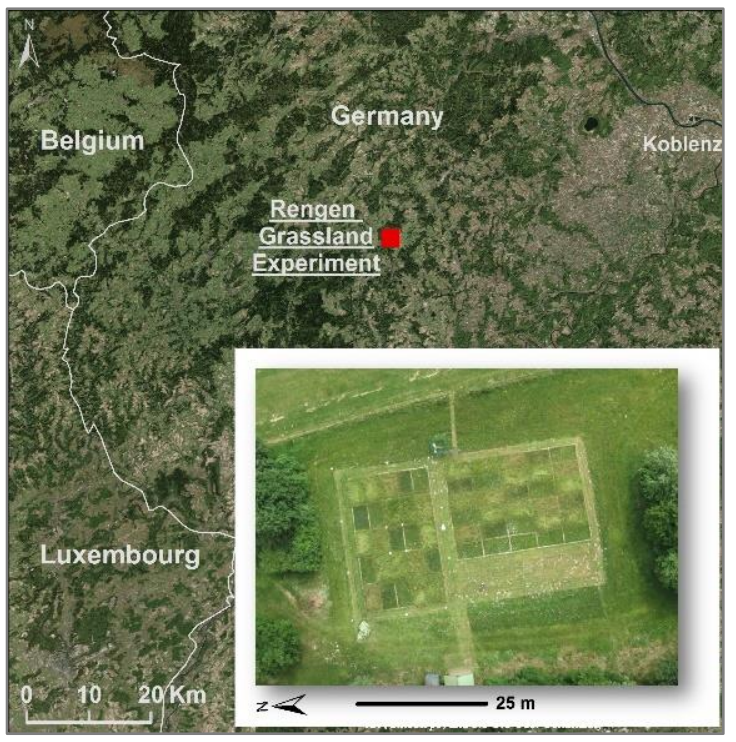

Figure 1. Overview of the Rengen Grassland Experiment (Inset photo: G. Bareth, 2014).

Throughout the growing season in 2014 continuous data acquisition was conducted including (i) destructive plant sampling, (ii) quantification of standing biomass, (iii) determination of floristic composition and (iv) hyperspectral measurements of canopy reflectance.

This study focuses on vegetation indices (VIs) on three consecutive dates of the first growth in 2014 (April $2^{\text {nd }}$, April $16^{\text {th }}$, and May $18^{\text {th }}$ ). Reflectance measurements were taken with a portable spectroradiometer (ASD FieldSpec3, Analytical Spectral Devices, Boulder, CO, USA) on 25 plots of the RGE from $1.5 \mathrm{~m}$ above canopy. Based on these measurements broad- and narrowband VIs were calculated per plot. Broadband VIs were calculated by simulating RapidEye bands using their spectral response function (Hollberg \& Schellberg 2017). For this study the Normalized Difference Vegetation Index (NDVI), the Green Normalized Vegetation Index (GNDVI), the
Optimized Soil Adjusted Vegetation Index (OSAVI) and the Leaf Chlorophyll Index (LCI) were calculated from broad- and narrow band reflectances, except the LCI was only calculated as broad band index.

\begin{tabular}{|c|c|c|}
\hline & Index Equation & Source \\
\hline NDVI & $\begin{array}{c}\left(\mathrm{R}_{\mathrm{NIR}}-\mathrm{R}_{\mathrm{R}}\right) / \\
\left(\mathrm{R}_{\mathrm{NIR}}+\mathrm{R}_{\mathrm{R}}\right)\end{array}$ & $\begin{array}{l}\text { Rouse et al. } \\
1974\end{array}$ \\
\hline OSAVI & $\begin{array}{c}(1+0.16) *\left(\left(\mathrm{R}_{\mathrm{NIR}}-\mathrm{R}_{\mathrm{R}}\right) /\right. \\
\left(\mathrm{R}_{\mathrm{NIR}}+\mathrm{R}_{\mathrm{R}}+0.16\right)\end{array}$ & $\begin{array}{l}\text { Rondeaux et } \\
\text { al. } 1996\end{array}$ \\
\hline GNDVI & $\begin{array}{c}\left(\mathrm{R}_{\mathrm{NIR}}-\mathrm{R}_{\mathrm{G}}\right) / \\
\left(\mathrm{R}_{\mathrm{NIR}}+\mathrm{R}_{\mathrm{G}}\right) \\
\end{array}$ & $\begin{array}{l}\text { Gitelson et al. } \\
1996\end{array}$ \\
\hline LCI & $\begin{array}{c}\left(\mathrm{R}_{\mathrm{NIR}}-\mathrm{R}_{\mathrm{RE}}\right) / \\
\left(\mathrm{R}_{\mathrm{NIR}}-\mathrm{R}_{\mathrm{R}}\right) \\
\end{array}$ & Datt 1999 \\
\hline nNDVI & $\begin{array}{c}\left(\mathrm{R}_{800}-\mathrm{R}_{670}\right) / \\
\left(\mathrm{R}_{800}+\mathrm{R}_{670}\right) \\
\end{array}$ & $\begin{array}{l}\text { Rouse et al. } \\
1974\end{array}$ \\
\hline nOSAVI & $\begin{array}{c}(1+0.16) *\left(\left(\mathrm{R}_{800}-\mathrm{R}_{670}\right) /\right. \\
\left.\left(\mathrm{R}_{800}+\mathrm{R}_{670}+0.16\right)\right)\end{array}$ & $\begin{array}{l}\text { Rondeaux et } \\
\text { al. } 1996\end{array}$ \\
\hline nGNDVI & $\begin{array}{c}\left(\mathrm{R}_{780}-\mathrm{R}_{550}\right) / \\
\left(\mathrm{R}_{780}+\mathrm{R}_{550}\right)\end{array}$ & $\begin{array}{l}\text { Gitelson et al. } \\
1996\end{array}$ \\
\hline
\end{tabular}

Table 1. Vegetation Indices from spectroradiometer measurements analysed in this study. $\mathrm{R}=$ reflectance (\%),

$\mathrm{R}_{\mathrm{R}}=$ red, $\mathrm{R}_{\mathrm{G}}=$ green, $\mathrm{R}_{\mathrm{RE}}=$ Red Edge, $\mathrm{R}_{\mathrm{NIR}}=$ near infrared, $R_{i}=$ reflectance in narrow band region $\left(R_{670}=\right.$

$670 \mathrm{~nm}$ ). Lower case $\mathrm{n}$ denotes narrow band index.

Parallel to reflectance measurements UAV-campaigns were flown over the RGE (April 6 ${ }^{\text {th }}$, April $16^{\text {th }}$, and May $\left.18^{\text {th }}\right)$, with focus on the 25 plots were spectral measurements are available. The UAV, a DJI ${ }^{\circledR}$ Phantom 2 quadrocopter, was equipped with a consumer grade Canon Powershot 110 camera.

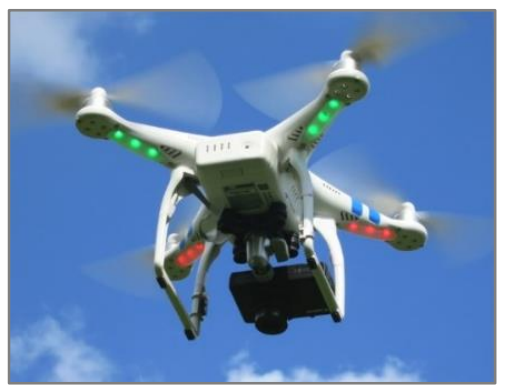

Figure 2. DJI ${ }^{\circledR}$ Phantom 2 equipped with Canon Powershot 110 (Photo G. Bareth, 2014).

Central to this study is the evaluation of a recently developed RGB-based VI, the RGBVI as described by Bendig et al. (2015), against VIs from the visible and nearinfrared spectrum. The RGBVI is computed from UAVbased RGB-imagery on a per pixel basis by the following equation (Bendig et al. 2015):

$$
\text { RGBVI }=\frac{\left(\mathrm{R}_{\mathrm{G}}\right)^{2}-\left(\mathrm{R}_{\mathrm{B}} * \mathrm{R}_{\mathrm{R}}\right)}{\left(\mathrm{R}_{\mathrm{G}}\right)^{2}+\left(\mathrm{R}_{\mathrm{B}} * \mathrm{R}_{\mathrm{R}}\right)}
$$

Where $\mathrm{R}=$ reflectance $(\%), \mathrm{R}_{\mathrm{R}}=$ red, $\mathrm{R}_{\mathrm{G}}=$ green, $\mathrm{R}_{\mathrm{B}}=$ blue.

To minimize the effect of changes in illumination on the UAV-based RGBVI, one overview image of the 25 plots

\footnotetext{
${ }^{1} \mathrm{https}: / /$ www.lap.uni-

bonn.de/forschung/forschungsprojekte/Spectral\%20Resp onse $\% 20$ of\%20Traits
} 
was acquired at about $50 \mathrm{~m}$ flying altitude per sampling date. 14 ground control points (GCPs) were evenly distributed on the experimental field and measured with a highly accurate RTK-GPS (Topcon HiperPro 5).

For multitemporal remote sensing based analyses of vegetation properties it is desirable to analyse data in comparable units of reflectance. The empirical line method (ELM) as described by Smith \& Milton (1999) is a simple and direct approach to calibrate DNs of imaging sensors to units of surface reflectance. The relationship between atsensor radiance and at-surface reflectance is estimated by measuring at least one spectrally stable reference target. By using two contrasting reference targets the effects of atmospheric radiance can be removed. The reference targets should be near lambertian and spectrally well characterized. Several studies showed a more robust estimation of correction equations, when more than two reference targets were deployed (Smith \& Milton 1999, Karpouzli \& Malthus 2003). The derived prediction equations, which account for changes in illumination and atmospheric effects, are applied band wise to obtain images in units of reflectance (Smith \& Milton, 1999).

In this study the Empirical Line Method was applied to UAV-based imagery from a consumer-grade camera to derive vegetation indices based on the red, green and blue bands. Therefor four reference targets in different shades of grey were placed on the ground near the 25 plots on each date of the UAV-campaigns (see Figure 3).

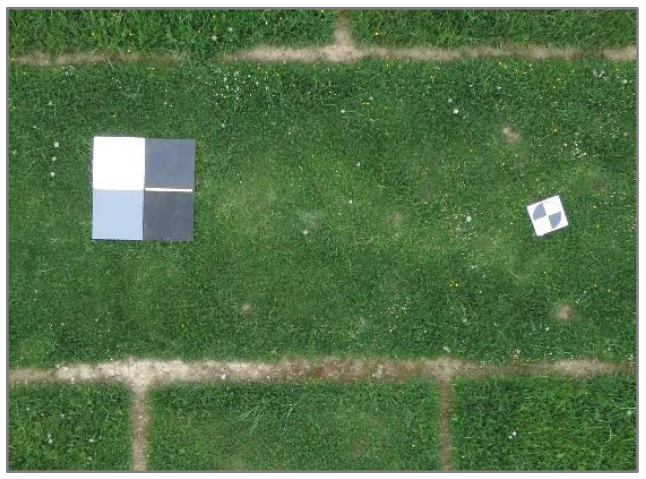

Figure 3. Reference targets (left) \& ground control point (right) at the Rengen Grassland Experiment (Photo G. Bareth 2014).

The reflectance of the targets was measured with an ASD FieldSpec3 under cloudless, constant solar illumination. The targets were visible in each of the above mentioned overview images acquired with the Canon Powershot 110. The DNs of the single bands were converted to a scale of $0-1$. To derive prediction equations per band the DNreadings per reference target were averaged and compared to the respecting spectroradiometer readings for the red, green and blue band respectively. The white reference target was left out of the prediction equation, since the DNreadings were highly saturated and resulted in an overestimation of values.

The resulting prediction equations were applied per band using the tool Raster Calculator in ArcMap (v.10.3). The RGBVI was calculated per pixel from the calibrated bands for each of the three sampling dates.
Comparison of UAV-based RGBVI and the VIs based on field measurements listed in Table 1 was conducted at plot level. To obtain mean values per plot of the RGBVI the tool Zonal Statistics as Table in ArcMap was applied. An inside buffer was applied to the plot-polygons to minimize border effects. The black polygons in Figure 4 represent the area for calculating mean values per plot. Coefficients of Determination $\left(\mathrm{R}^{2}\right)$ were computed based on linear regression models for each VI-pairing per sampling date in MS Excel.

\section{RESULTS}

Fig. XX displays the spatial variation of the RGBVI on the 25 sampling plots for the first (April $6^{\text {th }}$ ) and third (May $18^{\text {th }}$ ) sampling date based on the calibrated overview images.

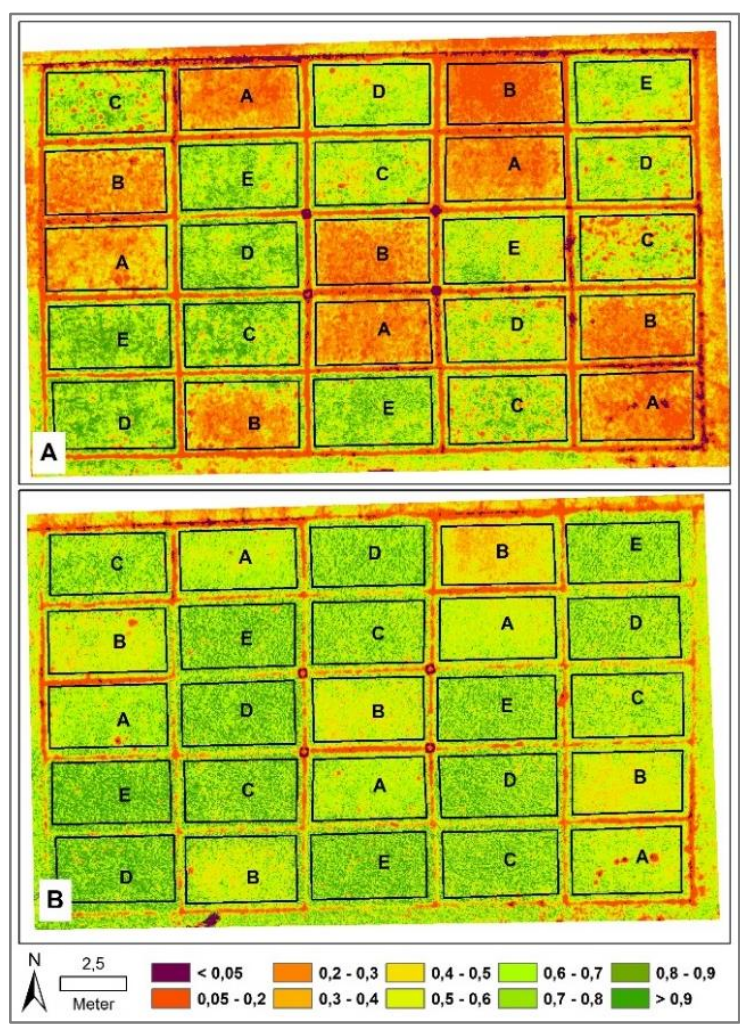

Figure 4. UAV-based RGBVI values for $6^{\text {th }}$ April (A) and $18^{\text {th }}$ May (B). Capital letters correspond to fertilizer treatments (Ca (A), CaN (B), CaNP (C), CaNPKCl (D),

$\mathrm{CaNPK}_{2} \mathrm{SO}_{4}(\mathrm{E})$ ). Black Polygons represent areas to compute mean values per plot.

In Fig. 4 (A) treatments of lower fertilizer input are clearly distinguishable from treatments with higher fertilizer input. Lower values of the RGBVI correspond to lower fertilizer inputs (plots $\mathrm{A}$ and $\mathrm{B}$ are $\mathrm{Ca}$ and $\mathrm{CaN}$-treatments respectively). On the third sampling date (Fig. 4 B) the RGBVI values express a lower range of values, but differences between lower and higher fertilizer inputs are still visible. Some plots show randomly distributed spots of low RGBVI values on the first sampling date (Fig 4 A). These spots reflect disturbances by rodents and are in more severe cases also visible after canopy closure on the third sampling date (e.g. lower right corner of Fig. 4 B). 
Comparing the UAV-based calibrated RGBVI with spectroradiometer-derived calibrated VIs indicates a pattern. Table 2 summarizes the $\mathrm{R}^{2}$ values and standard errors (SE) for the three sampling dates.

\begin{tabular}{l|l|l|l|l|l|l} 
& \multicolumn{2}{|c|}{$\mathbf{0 2 . 0 4 . 2 0 1 4}$} & \multicolumn{1}{|c|}{$\mathbf{1 6 . 0 4 . 2 0 1 4}$} & \multicolumn{2}{c}{$\mathbf{1 6 . 0 5 . 2 0 1 4}$} \\
\hline Index & $\mathrm{R}^{2}$ & $\mathrm{SE}$ & $\mathrm{R}^{2}$ & $\mathrm{SE}$ & $\mathrm{R}^{2}$ & $\mathrm{SE}$ \\
\hline NDVI & 0.91 & 0.05 & 0.78 & 0.05 & 0.2 & 0.09 \\
\hline GNDVI & 0.91 & 0.05 & 0.67 & 0.06 & 0.01 & 0.1 \\
\hline OSAVI & 0.9 & 0.06 & 0.84 & 0.04 & 0.14 & 0.09 \\
\hline LCI & 0.72 & 0.09 & 0.5 & 0.08 & 0.02 & 0.1 \\
\hline nNDVI & 0.92 & 0.05 & 0.8 & 0.05 & 0.28 & 0.08 \\
\hline nGNDVI & 0.91 & 0.05 & 0.64 & 0.06 & 0.00 & 0.1 \\
\hline nOSAVI & 0.9 & 0.06 & 0.85 & 0.4 & 0.18 & 0.09 \\
\hline
\end{tabular}

Table 2. $\mathrm{R}^{2}$ values and standard error (SE) for regression analysis of RGBVI vs. VIs listed in Table 1 ( $\mathrm{p}<0.01)$

For the first sampling date all VIs show a strong correlation with the RGBVI derived from calibrated UAVimagery with $\mathrm{R}^{2}$ values of 0.9 or higher, except for the LCI $\left(R^{2} 0.7\right)$. On the second sampling date the $R^{2}$ values range from 0.5 (LCI) to 0.85 (narrowband OSAVI). However, the $\mathrm{R}^{2}$ values on the third sampling date in mid-May show a very weak $\left(\mathrm{R}^{2}<0.3\right)$ or in the case of the GNDVI (broadand narrowband) and LCI no correlation.

Figures 5-7 show the regression lines for the three sampling dates exemplary for the broad band NDVI vs. UAV-imagery derived RGBVI.

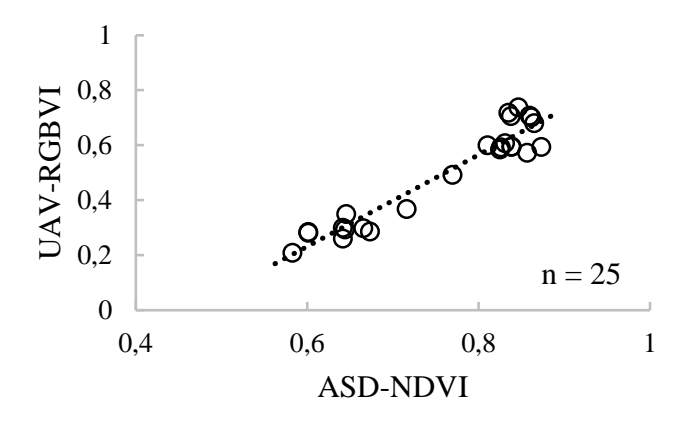

Figure 5. Regression of the UAV-based RGBVI and ASD Fieldspec3-based NDVI per plot for the first sampling date (02.04. \& 06.04.2014, ASD \& UAV respectively).

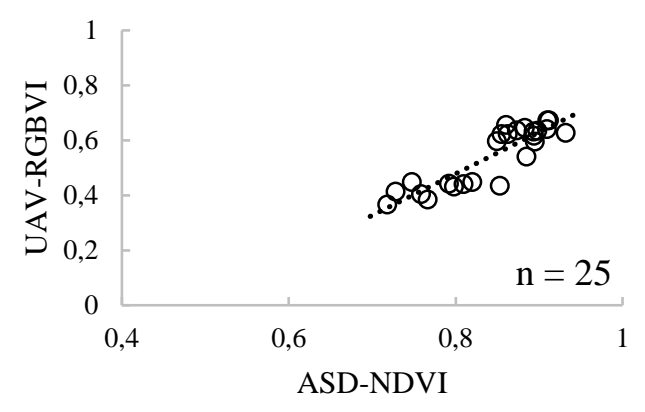

Figure 6. Regression of the UAV-based RGBVI and ASD Fieldspec3-based NDVI per plot for the second sampling date (16.04.2014, ASD \& UAV).

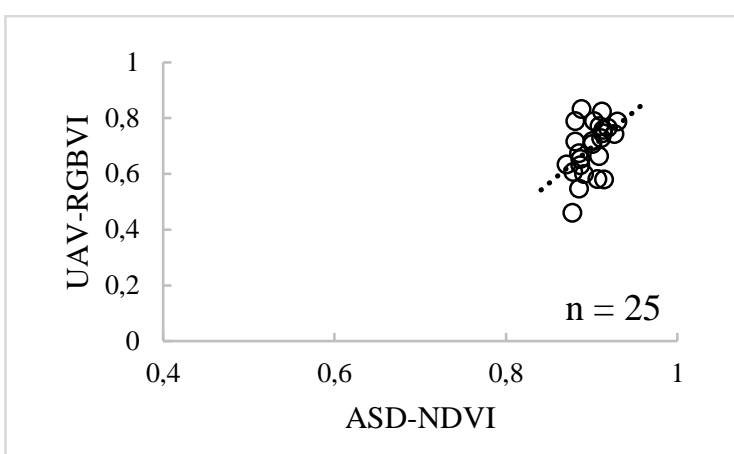

Figure 7. Regression of the UAV-based RGBVI and ASD Fieldspec3-based NDVI per plot for the third sampling date (18.05.2014, ASD \& UAV).

In all three sampling dates the RGBVI shows a higher range of values while the range of NDVI values decrease with advancing growth and canopy closure. Hence on the third sampling date in mid-May the NDVI values are at about 0.9 with only little variation, while the RGBVI values range from 0.46 to 0.83 .

\section{DISCUSSION \& CONCLUSION}

The primary aim of this study is to evaluate a recently developed VI based on high resolution UAV RGBimagery, the RGBVI, against widely applied VIs in the visible to near-infrared spectrum. In order to have comparable units for multitemporal analysis of changes in reflectance of the different grassland communities, the UAV-based images were calibrated to units of reflectance by using the Empirical Line Method (ELM).

Using three reference targets is acknowledged to minimize errors in computing the prediction equation (Smith \& Milton 1999), although a thorough investigation of errors was not applied in this study. One drawback might be, that the radiometric response curve of the camera is not known and should be measured with a monochromatic light source as recommended by Hunt et al. (2005).

The approach of using an overview image of the area of interest instead of image-mosaics to compute the RGBVI as discussed by Bendig et al. (2015) and Rasmussen et al. (2016) seemed to work well and partly eliminated the problem of varying incident light.

The correlation of the UAV-based RGBVI and the spectroradiometer based VIs shows a strong relationship in the first sampling date but decreased to the third sampling date when canopy closure is reached in midMay. These findings were also observed by Bareth et al. (2015) for grassland and Bareth et al. (2016) for wheat, but with uncalibrated RGBVI-values. Hunt et al. (2013) found similar results for wheat for the Triangulated Greenness Index (TGI), an RGB-based Index with a comparable layout to the RGBVI.

Common VIs such as the NDVI tend to saturate with canopy closure and higher biomass levels and increasing Leaf Area Index (LAI) when reflectance in the red part of the spectrum decreases (Hunt et al. 2005, Gitelson et al. 2002). The RGBVI seems to be more sensitive to subtle changes in greenness, hence it displays a wider range of 
values also in later growing stages. This can be explained by the fact that reflectance in the visible spectrum is mainly dominated by pigment content and composition (Gitelson et al. 2002). The RGBVI emphasises the reflectance differences caused by chlorophyll-absorption (Bendig et al. 2015), which may present information on spatial variability of Nitrogen supply (Hunt et al. 2013).

However, further analysis should be directed towards the performance and validation of the RGBVI on conventionally managed grassland fields for an entire growing season.

Finally, the presented results indicate, that calibrated RGB-based VIs have the potential to support or substitute hyperspectral field measurements to facilitate management decisions on grasslands.

\section{REFERENCES}

Bareth, G., Bolten, A., Hollberg, J., Aasen, H., Burkart, A., Schellberg, J. 2015. Feasibility study of using noncalibrated UAV-based RGB imagery for grassland monitoring: Case study at the Rengen Long-term Grassland Experiment (RGE), Germany. Proceedings of the DGPF Annual Conference 2015. - Cologne, Germany http://www.dgpf.de/src/tagung/jt2015/proceedings/ papers/07_DGPF2015_Bareth_et_al.pdf.

Bareth, G., Bolten, A., Gnyp, M. L., Reusch, S., Jasper, J. 2016. Comparison of uncalibrated RGBVI with spectrometer-based NDVI derived from UAV sensing systems on field scale. The International Archives of the Photogrammetry, Remote Sensing and Spatial Information Sciences, Volume XLI-B8, 2016 XXIII ISPRS Congress, 12-19 July 2016, Prague, Czech Republic, pp. 837-843. http://www.int-arch-photogramm-remote-sens-spatialinf-sci.net/XLI-B8/837/2016/isprs-archives-XLI-B8-8372016.pdf.

Bendig, J., Yu, K., Aasen, H., Bolten, A., Bennertz, S., Broscheit, J., Gnyp, M.L., and Bareth, G., 2015. Combining UAV-based plant height from crop surface models, visible, and near infrared vegetation indices for biomass monitoring in barley. International Journal of Applied Earth Observation and Geoinformation, 39, pp. 79-87. doi: 10.1016/j.jag.2015.02.012.

Chytry, M., Hejcman, M., Hennekens, S., Schellberg, J. 2009. Changes in vegetation types and Ellenberg indicator values after 65 years of fertilizer application: evidence from the Rengen Grassland Experiment, Germany. Applied Vegetation Science, 12, pp. 167-176. doi:10.1111/j.1654-109X.2009.01011.x.

Datt, B. 1999. A new reflectance index for remote sensing of chlorophyll content in higher plants: Tests using eucalyptus leaves. Journal of Plant Physiology, 154, pp. 30-36.

Gitelson, A.A., Kaufman, Y.J., Merzlyak, M.N. 1996. Use of a green channel in remote sensing of global vegetation from EOS-MODIS. Remote Sensing of Environment, 58, pp. 289-298.
Gitelson, A., Kaufman, Y., Stark, R., Rundquist, D. 2002. Novel algorithms for remote estimation of vegetation fraction. Remote Sensing of Environment, 80, pp. 76-87.

Hollberg, J., Schellberg, J. 2017. Distinguishing Intensity Levels of Grassland Fertilization Using Vegetation Indices. Remote Sensing, 9 (1), pp. 81(20). doi:10.3390/rs9010081.

Hunt, E.R., Cavigelli, M., Daughtry, C., McMurtrey, J., Walthall, C. 2005. Evaluation of Digital Photography from Model Aircraft for Remote Sensing of Crop Biomass and Nitrogen Status. Precision Agriculture, 6, pp. 359-378.

Hunt, E.R., Daughtry, C., Eitel, J., Long, D. 2011. Remote Sensing Leaf Chlorophyll Content Using a Visible Band Index. Agronomy Journal, 103 (4), pp. 1090-1099.

Hunt, E. R., Doraiswamy, P., McMurtrey, J., Daughtry, C., Perry, E. 2013. A visible band index for remote sensing leaf chlorophyll content at the canopy scale. International Journal of Applied Earth Observation and Geoinformation, 21, pp. 103-112.

Karpouzli, E., Malthus, T. 2003. The empirical line method for the atmospheric correction of IKONOS imagery. International Journal of Remote Sensing, 24 (5), pp. 1143-1150. doi: 10.1080/0143116021000026779.

Rasmussen, J., Ntakos, G., Nielsen, J., Svensgaard, J., Poulsen, R., Christensen, S., 2016 Are vegetation indices derived from consumer-grade cameras mounted on UAVs sufficiently reliable for assessing experimental plots? European Journal of Agronomy, 74, pp. 75-92. doi: 10.1016/j.eja.2015.11.026.

Rondeaux, G., Steven, M., Baret, F., 1996. Optimization of soil-adjusted vegetation indices. Remote Sensing of Environment 55, pp. 95-107.

Rouse, J., Jr., Haas, R., Schell, J., Deering, D. 1974. Monitoring vegetation systems in the Great Plains with ERTS. NASA Special Publication, 351, pp. 309-317.

Schellberg, J., Möseler, R., B.M., Kühbauch, W., Rademacher, I. 1999. Long-term effects of fertilizer on soil nutrient concentration, yield, forage quality and floristic composition of a hay meadow in the Eifel Mountains, Germany. Grass and Forage Science, 54, pp. 195-207. doi: 10.1046/j.1365-2494.1999.00166.x

Schellberg, J., Hill, M.J., Gerhards, R., Rothmund, M., Braun, M. 2008. Precision agriculture on grassland: applications, perspectives and constraints - a review. European Journal of Agronomy 29, pp. 59-71. doi: 10.1016/j.eja.2008.05.005.

Smith, G., Milton, E. 1999. The use of the empirical line method to calibrate remotely sensed data to reflectance. International Journal of Remote Sensing, 20 (13), pp. 2653-2662. doi: 10.1080/014311699211994.

Tilly, N., Aasen, H., and Bareth, G., 2015: Fusion of plant height and vegetation indices for the estimation of barley biomass. Remote Sensing, 7(9), pp.11449-11480. doi:10.3390/ rs70911449. 